Review

\title{
In vivo Hepatocyte Genome Manipulation via Intravenous Injection of Genome Editing Components
}

\author{
Shingo Nakamura ${ }^{1,}{ }^{*}$, Naoko Ando ${ }^{1}$, Masayuki Ishihara ${ }^{1}$, Masahiro Sato ${ }^{2}$
}

1. Division of Biomedical Engineering, National Defense Medical College Research Institute, Saitama 359-8513, Japan; E-Mails: snaka@ndmc.ac.jp; naoandokoro@gmail.com; ishihara@ndmc.ac.jp

2. Section of Gene Expression Regulation, Frontier Science Research Center, Kagoshima University, Kagoshima 890-8544, Japan; E-Mail: masasato@m.kufm.kagoshima-u.ac.jp

* Correspondence: Shingo Nakamura; E-Mail: snaka@ndmc.ac.jp

Academic Editor: Joep Geraedts

Special Issue: Genome Editing

OBM Genetics

2020, volume 4, issue 4

doi:10.21926/obm.genet.2004119
Received: August 09, 2020

Accepted: October 27, 2020

Published: November 16, 2020

\begin{abstract}
The liver is a major organ with a wide range of functions, including detoxification, protein synthesis, and bile production. Liver dysfunction causes liver diseases such as hepatic cirrhosis and hepatitis. To explore the pathogenesis of these liver diseases, and the therapeutic agents against them, mice have been widely used as animal models. Genetic manipulation is easy in mice via the administration of nucleic acids (NAs) in the tail-vein. In particular, hydrodynamics-based gene delivery (HGD) is a method based on the introduction of a large volume of NA-containing solution over a short period in the tail-vein. It is recognized as a powerful tool to efficiently transfect hepatocytes. Genome editing, as illustrated by the clustered regularly interspaced short palindromic repeats (CRISPR)/CRISPRassociated protein-9 nuclease (Cas9) (CRISPR/Cas9) system, has also been recognized as a powerful tool to manipulate target genes in host genomes. Recently, studies have described the tail-vein-mediated introduction of genome editing components for the generation of liver tumors, correction of mutated genes causing liver dysfunction, and generation of mice
\end{abstract}

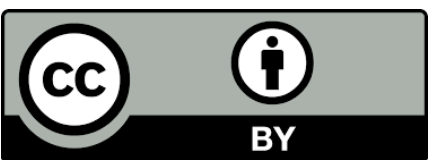

(C) 2020 by the author. This is an open access article distributed under the conditions of the Creative Commons by Attribution License, which permits unrestricted use, distribution, and reproduction in any medium or format, provided the original work is correctly cited. 
with liver disease. More importantly, this HGD method can bypass the need to create mouse progeny carrying the targeted mutation in their germline. In this review, the past and present achievements of liver-targeted manipulation achieved via intravenous injection of genome editing components will be summarized.

\section{Keywords}

CRISPR/Cas9; disease model mice; gene correction; genome editing; hepatic cirrhosis; hepatitis; hydrodynamics; in vivo gene delivery; tail-vein injection

\section{Introduction}

The liver is a major organ that plays an important role in nutrient metabolism, synthesis of glucose and lipids, and detoxification of drugs and xenobiotics. Liver dysfunction causes liver diseases such as hepatic cirrhosis and hepatitis.

Genetic engineering technology helps in elucidating the functions of genes isolated from animal liver, and the mechanisms leading to the pathogenesis of liver disease. This information is partly derived from molecular biological analysis using cultured hepatocytes. However, in vivo experiments are required for such investigations.

The transgenic $(\mathrm{Tg})$ approach is based on the zygote-microinjection or viral infection of zygotes and has been extensively employed to evaluate the genes of interest (GOI) in organisms, but $\mathrm{Tg}$ animal production and maintenance are considered time-consuming and laborious [1]. Furthermore, the generation of $\mathrm{Tg}$ animals is often associated with biased expression of the transgene involved due to transgene position effects (or gene silencing) potentially caused by 'transgene random integration' into the host chromosome. Therefore, insertion of a transgene into a safe harbor site, as exemplified by the ROSA26 locus, has been recommended as a promising tool conferring unbiased expression of transgenes [2]. However, for the establishment and maintenance of basic Tg mouse lines, animal models for the targeted insertion of a transgene into the ROSA26 locus is required. At the same time, the use of an appropriate promoter that can drive the expression of a downstream target cDNA in the liver is also important. Most tissuespecific promoters are weak compared to stronger, but constitutively expressed, viral promoters [3]. Although there are methods to increase promoter activity while maintaining tissue specificity, such systems are complex and require the production of $\mathrm{Tg}$ lines [3-5].

Hepatocytes are readily accessible via the bloodstream. The endothelium of hepatic sinusoids allows macromolecules, such as viral particles, to cross the endothelium and reach the hepatocytes. Thus, tail-vein gene delivery has been considered as one of the main noninvasive approaches to transfect hepatocytes. In 1988, a successful non-viral vector-based delivery targeting hepatocytes that employed the asialoglycoprotein receptor system was reported [6]. However, low transgene expression and the absence of sustained expression limited the development of this system. Another noninvasive and simple approach pioneered by the Wolff group employed intravenous introduction of nucleic acids (NAs) to liver cells in vivo [7]. In the initial stage of this approach, NAs are introduced in the form of naked plasmid DNA or DNA complexed with gene delivery accelerating agents such as liposomes $[7,8]$. Indeed, several 
internal organs can be successfully transfected with exogenous DNA, but transgene expression is transient and unstable [9]. However, recently, sustained transgene expression has become possible when both the piggyBac $(P B)$ transposon vector (carrying a transgene) and $P B$ transposase expression vector are intravenously introduced into mice as naked DNA, or DNA complexed with gene delivery accelerating agents [10-12]. The $P B$ gene delivery system is one of the transposons that confer the integration of a target gene into host chromosomes with the aid of transposase activity $[13,14]$. Therefore, sustained expression of a transgene is thought to be caused by the chromosomal integration of the transgene. These findings suggested that the exploration of $\mathrm{GO}$ is possible in mice that have been subjected to intravenous NA injection, where $\mathrm{Tg}$ mouse production is not always required.

Since the report by Wolff et al. in 1990, several methods have been described for delivering exogenous DNA to liver cells. These include direct 'intrahepatic' or 'intraportal' injections of NAs into exposed liver tissue, physical gene delivery such as gene guns, electroporation, sonoporation, conventional tail-vein injections, and hydrodynamic-based gene delivery (HGD) [15]. Viral vectors are considered the most efficient tool to achieve efficient gene transfer to liver cells in vivo. Adenoviral (AV), retroviral (RV), and adeno-associated viral (AAV) vectors still represent the most promising vectors. Successful infection of rat hepatocytes by AV vectors was first reported in the early 1990s, owing to the vectors' ability to infect quiescent hepatocytes to a large extent [16]. However, the infection triggers an immune response, leading to cytotoxic elimination of transduced hepatocytes. The efficiency of RV vectors to transduce hepatocytes in vivo was evaluated and found to be high [17]. However, it was later found that an immune response against the transgene product was elicited when large amounts of RV vectors were administered in vivo [18]. AAV vectors are promising tools to transduce liver cells in vivo. These vectors are devoid of all viral genes and therefore do not induce a virus-directed immune response. Many studies have shown that AAV vectors can transduce hepatocytes for a prolonged duration in vivo [19-21].

As described previously, the barrier for successful hepatocyte-targeted gene delivery is the plasma membranes of hepatocytes and epithelial cells with a sinusoidal structure. Therefore, the listed gene delivery approach involves the disruption of the aforementioned barriers through pressure, shock waves, electric pulse, ultrasound, or hydrodynamic pressure. Except for 'conventional' tail-vein injections and HGD, all these approaches accompany surgical treatment, which is highly invasive to individuals. By contrast, HGD has been developed as a noninvasive and convenient tool to transfect hepatocytes efficiently in vivo [22-24].

In Table 1, recent achievements in hepatocyte genome manipulation using the tail-vein injection approach are shown. As listed, HGD is most frequently used for delivering exogenous DNA to liver cells. 
Table 1 Summary of manipulation of rodent hepatocyte genome using tail-vein injection.

\begin{tabular}{|c|c|c|c|c|c|}
\hline Method for gene delivery & Type of genome editing & $\begin{array}{l}\text { Type of } \\
\text { manipulation }\end{array}$ & $\begin{array}{l}\text { Target } \\
\text { genes }\end{array}$ & Note & References \\
\hline HGD & $\begin{array}{l}\text { CRISPR/Cas9 } \\
\text { All-in-one plasmid }\end{array}$ & KO & $\begin{array}{l}\text { p53 } \\
\text { Pten }\end{array}$ & $\begin{array}{l}\text { Induction of multifocal tumors in adult mouse liver } \\
\text { after carbon tetrachloride treatment }\end{array}$ & {$[25]$} \\
\hline HGD & $\begin{array}{l}\text { CRISPR/Cas9 } \\
\text { All-in-one plasmid + ssDNA }\end{array}$ & $\mathrm{KI}$ & Fah & $\begin{array}{l}\text { Using a mouse model }\left(\mathrm{Fah}^{-/-}\right) \text {of the human } \\
\text { tyrosinemia, the mutation was corrected via somatic } \\
\text { homologous recombination }\end{array}$ & {$[26]$} \\
\hline HGD & $\begin{array}{l}\text { CRISPR/Cas9 } \\
\text { AV vector }\end{array}$ & KO & Pten & $\begin{array}{l}\text { Four months after vector infusion, mice receiving the } \\
\text { Pten gene-editing AV vector showed massive } \\
\text { hepatomegaly and features of NASH }\end{array}$ & [27] \\
\hline HGD & $\begin{array}{l}\text { CRISPR/Cas9 } \\
\text { All-in-one plasmid }+ \text { SB } \\
\text { transposons }\end{array}$ & KO & $\begin{array}{l}\text { Multiplex } \\
\text { genes, } \\
\text { including } \\
\text { Trp53, } \\
\text { Smad4, } \\
\text { Pten, } \\
\text { Cdkn2a, } \\
\text { and Apc }\end{array}$ & $\begin{array}{l}\text { CRISPR/Cas9-based targeted somatic multiplex- } \\
\text { mutagenesis resulted in the generation of } 1-3 \text { small } \\
\text { tumors per mouse } 20-30 \text { weeks after HGD, and proven } \\
\text { useful for recessive genetic screening or high- } \\
\text { throughput cancer gene validation in mice }\end{array}$ & [28] \\
\hline HGD & $\begin{array}{l}\text { CRISPR/Cas9 } \\
\text { All-in-one plasmid }\end{array}$ & KO & $\begin{array}{l}\text { HBV } \\
\text { genome }\end{array}$ & $\begin{array}{l}\text { Using the new mouse model carrying HBV } \operatorname{cccDNA} \text {, the } \\
\text { treated mice exhibited low levels of } \operatorname{cccDNA} \text { and HBV } \\
\text { protein }\end{array}$ & [29] \\
\hline HGD & $\begin{array}{l}\text { CRISPR/Cas9 } \\
\text { All-in-one plasmid + sSDNA }\end{array}$ & $\mathrm{KI}$ & F9 & $\begin{array}{l}\text { Hemophilia B mouse model (carrying novel Y371D } \\
\text { mutation) is rescued through correction of over } 0.56 \% \\
\text { of } F 9 \text { alleles in hepatocytes }\end{array}$ & {$[30]$} \\
\hline HGD & $\begin{array}{l}\text { CRISPR/Cas9 } \\
\text { All-in-one plasmid }\end{array}$ & KO & $\begin{array}{l}\text { HBV } \\
\text { genome }\end{array}$ & $\begin{array}{l}\text { Using the M-TgHBV mouse model, the treated mice } \\
\text { exhibited decreased HBsAg in sera and liver }\end{array}$ & [31] \\
\hline
\end{tabular}




\begin{tabular}{|c|c|c|c|c|c|}
\hline HGD & $\begin{array}{l}\text { CRISPR/Cas9 } \\
\text { All-in-one plasmid }\end{array}$ & KO & $\begin{array}{l}\text { HBV } \\
\text { genome }\end{array}$ & $\begin{array}{l}\text { Using the HBV-Tg mice, the treated mice exhibited a } \\
\text { reduction in serum surface-antigen levels by } 99.91 \\
\pm 0.05 \% \text { and lowered serum HBV DNA }\end{array}$ & [32] \\
\hline $\begin{array}{l}\text { Conventional tail-vein } \\
\text { injection }\end{array}$ & $\begin{array}{l}\text { CRISPR/Cas9 } \\
\text { rAAV9 }\end{array}$ & KO & $\begin{array}{l}\text { HIV-1 } \\
\text { genome }\end{array}$ & $\begin{array}{l}\text { Using Tg rats carrying HIV-1 DNA, the treated animals } \\
\text { exhibited a decreased level of viral gene expression in } \\
\text { circulating blood lymphocytes }\end{array}$ & [33] \\
\hline HGD & $\begin{array}{l}\text { CRISPR/Cas9 } \\
\text { gRNA alone injected }\end{array}$ & KO & $A l b$ & $\begin{array}{l}\text { Using Cas9-expressing Tg mice (sCAT), approximately } \\
1 / 1000 \text { cells are successfully transfected, and almost all } \\
\text { these fluorescent cells are genome-edited single } \\
\text { hepatocytes }\end{array}$ & {$[34,35]$} \\
\hline HGD & $\begin{array}{l}\text { CRISPR/Cas9 } \\
\text { piggyBac transposons }\end{array}$ & KO & $\begin{array}{l}\text { Various } \\
\text { genes, } \\
\text { including } \\
\text { putative } \\
\text { TSGs }\end{array}$ & $\begin{array}{l}\text { An in vivo genome-wide screening in mice is conducted, } \\
\text { and genes mediating liver tumorigenesis, including } \\
\text { known and unknown TSGs were identified }\end{array}$ & [36] \\
\hline HGD & $\begin{array}{l}\text { CRISPR/Cas9 } \\
\text { All-in-one plasmid }\end{array}$ & KO & $\begin{array}{l}\text { Hsp40 } \\
\text { DNAJB1 } \\
\text { PRKACA }\end{array}$ & $\begin{array}{l}\text { To create mouse models for FL-HCC, FVB/N mice were } \\
\text { subjected to HGD. } 14 \text { months after delivery, Dnajb1- } \\
\text { Prkaca gene fusion was observed, and liver neoplasms } \\
\text { were developed }\end{array}$ & [37] \\
\hline HGD & $\begin{array}{l}\text { CRISPR/Cas9 } \\
\text { All-in-one plasmid }\end{array}$ & KO & $\begin{array}{l}\text { DNAJB1 } \\
\text { PRKACA }\end{array}$ & $\begin{array}{l}\text { To create mouse models for FL-HCC, FVB/N mice were } \\
\text { subjected to HGD. Liver tumors } 16 \text { to } 24 \text { months post- } \\
\text { injection were induced, similar to FL-HCC }\end{array}$ & [38] \\
\hline HGD & $\begin{array}{l}\text { CRISPR/Cas9 } \\
\text { All-in-one plasmid }\end{array}$ & KO & $p 53$ & $\begin{array}{l}\text { Isolation of genes found to be up-regulated after tumor } \\
\text { suppressor loss. Four candidate liver tumor suppressor } \\
\text { genes (Nf1, Plxnb1, Flrt2, and B9d1) were newly } \\
\text { identified }\end{array}$ & [39] \\
\hline HGD & $\begin{array}{l}\text { CRISPR/Cas9 } \\
\text { All-in-one plasmid }\end{array}$ & KO & $\begin{array}{l}\text { p53 } \\
\text { Pten }\end{array}$ & $\begin{array}{l}\text { Disruption of both } p 53 \text { and Pten induces liver } \\
\text { tumorigenesis in HBV-Tg mice, leading to the induction }\end{array}$ & [40] \\
\hline
\end{tabular}




\begin{tabular}{|c|c|c|c|}
\hline HGD & $\begin{array}{l}\text { CRISPR/Cas9 } \\
\text { All-in-one plasmid }\end{array}$ & KO & Pten \\
\hline HGD & $\begin{array}{l}\text { CRISPR/Cas9 } \\
\text { All-in-one plasmid + ssDNA }\end{array}$ & $\mathrm{KI}$ & F9 \\
\hline HGD & $\begin{array}{l}\text { CRISPR/Cas9 } \\
\text { All-in-one plasmid } \\
\text { CRISPR/Cas9 }\end{array}$ & KO & Pten \\
\hline HGD & $\begin{array}{l}\text { All-in-one plasmid + MMEJ } \\
\text { donor plasmid }\end{array}$ & $\mathrm{KI}$ & Fah \\
\hline $\begin{array}{l}\text { Conventional tail-vein } \\
\text { injection }\end{array}$ & $\begin{array}{l}\text { CRISPR/Cas9 } \\
\text { rAAV9 }\end{array}$ & KO & $\begin{array}{l}\text { Putative } \\
\text { TSGs }\end{array}$ \\
\hline HGD & $\begin{array}{l}\text { CRISPR/Cas9 } \\
\text { All-in-one plasmid }\end{array}$ & KO & Hpd \\
\hline $\begin{array}{l}\text { HGD into facial vein } \\
\text { injection at } 2-3 \text { days } \\
\text { after birth }\end{array}$ & $\begin{array}{l}\text { CRISPR/Cas9 } \\
\text { All-in-one plasmid + ssDNA }\end{array}$ & $\mathrm{KI}$ & IDUA \\
\hline $\begin{array}{l}\text { Facial vein injection at } \\
1-2 \text { days after birth }\end{array}$ & $\begin{array}{l}\text { CRISPR/Cas9 rAAV9 with } \\
\text { liver-specific promoter }\end{array}$ & KO & F9 \\
\hline HGD & $\begin{array}{l}\text { CRISPR/Cas9 } \\
\text { rAAV8 + BDDF8 donor } \\
\text { plasmid }\end{array}$ & $\mathrm{KI}$ & $A l b$ \\
\hline
\end{tabular}

\section{of HCC}

Pten loss and Nras overexpression (via SB transposon) cause HCC development in mice

Using an F9 mutant HB mouse model, $62.5 \%$ of the treated mice showed a detectable gene correction $(>1 \%)$ in the $F 9$ alleles of hepatocytes, which was sufficient to remit the coagulation deficiency Pten KO in rat liver resulted in severe lipid deposition, similar to the phenotype associated with NAFLD

MMEJ-based gene correction strategy was successful for the rescue of $\mathrm{Fah}^{-/-}$mice showing liver failure

All mice developed liver cancer and died within four months. rAAV-mediated autochthonous CRISPR screens are proven useful for mapping a provisional functional cancer genome atlas of tumor suppressors in vivo Using SLiK, it is possible to collect (or concentrate) hepatocytes with KO phenotype for a specific gene Using MPS I mouse model, there was an increased IDUA activity and decreased GAG storage, especially in the lungs and heart Cas9 expression was restricted mainly to the liver. Indels were evident in the liver (up to 50\%) in F9 gene, leading to a loss of F9 activity and the emergence of a bleeding phenotype, consistent with $\mathrm{HB}$

Using a mouse model of hemophilia A, completely reconstituting serum $\mathrm{F} 8$ activity was observed 


\section{Conventional tail-vein}

injection

HGD

Conventional tail-vein

injection

\section{CRISPR/Cas9}

rAAV8 + rAAV8-BDDF8

\section{CRISPR/Cas9}

All-in-one plasmid + donor plasmid

$\mathrm{KI}$

KI

-actin

p53

Gene

correction

Fah

ABE

Intein-split base editor
Gene

correction
Using a mouse model of hemophilia A, increased

plasma levels of FVIII and restoration of blood clotting properties were observed

$\mathrm{KI}$ of oncogenic Ras into the $\beta$-actin locus and loss of p53 efficiently induced intrahepatic cholangiocarcinoma in mice

Using a mouse model of the human tyrosinemia, the $A B E$ treatment partially restored splicing, generated Fah-positive hepatocytes in the liver, and rescued weight loss

Using a mouse model of the human phenylketonuria (PKU), the intein-split base editor treatment restored the PKU-associated phenotype

Abbreviations: ABE, adenine base editor; Alb, Albumin; Apc, adenomatous polyposis coli; AV, adenovirus; BDDF8, B domain-deleted F8; cccDNA, covalently closed circular DNA; Cdkn2a, cyclin-dependent kinase inhibitor 2A; Fah, fumarylacetoacetate hydrolase; FL-HCC, fibrolamellar hepatocellular carcinoma; F9, Factor IX; F8, FVIII or factor 8; GAG, glycosaminoglycans; gRNA, guide RNA; HB, hepatitis B; HBsAg, hepatitis B virus antigen; HBV, hepatitis B virus; HCC, hepatocellular carcinoma; HGD, hydrodynamics-based gene delivery; HIV-1, human immunodeficiency virus-1; Hpd, 4-hydroxyphenylpyruvate dioxygenase; Hsp40 DNAJB1, DnaJ heat shock protein family member B1; IDUA, alpha-L-iduronidase; KI, knock-in; KO, knock out; M-TgHBV, hepatitis B virus transgenic mice; MMEJ, microhomology-mediated end-joining; MPS I, mucopolysaccharidosis type I; NAFLD, nonalcoholic fatty liver disease; NASH, nonalcoholic steatohepatitis; Pah, phenylalanine hydroxylase; PKU, phenylketonuria; PRKACA, protein kinase CAMP-activated catalytic subunit alpha; rAAV, recombinant adeno-associated virus; SB, Sleeping Beauty; SLiK, somatic liver knockout; Smad4, SMAD family member 4; ssDNA, single-stranded DNA; Tg, transgenic; Trp53, cellular tumor antigen p53; TSGs, tumor suppressor genes. 
(a)

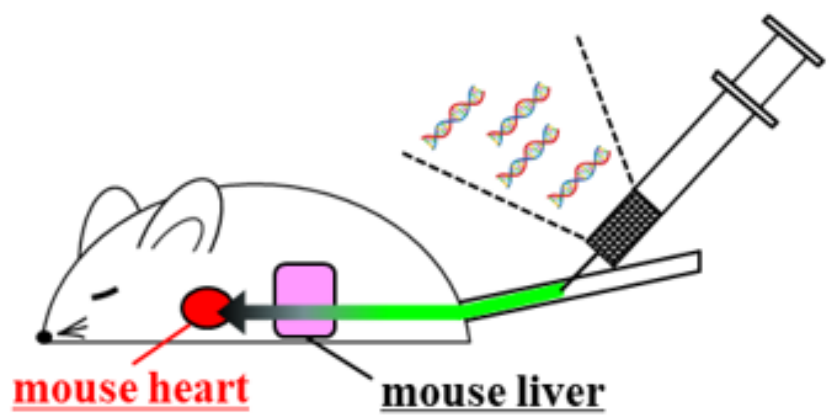

(b)

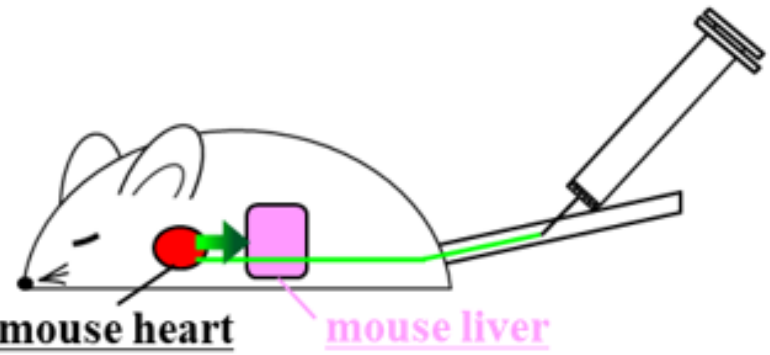

(c)

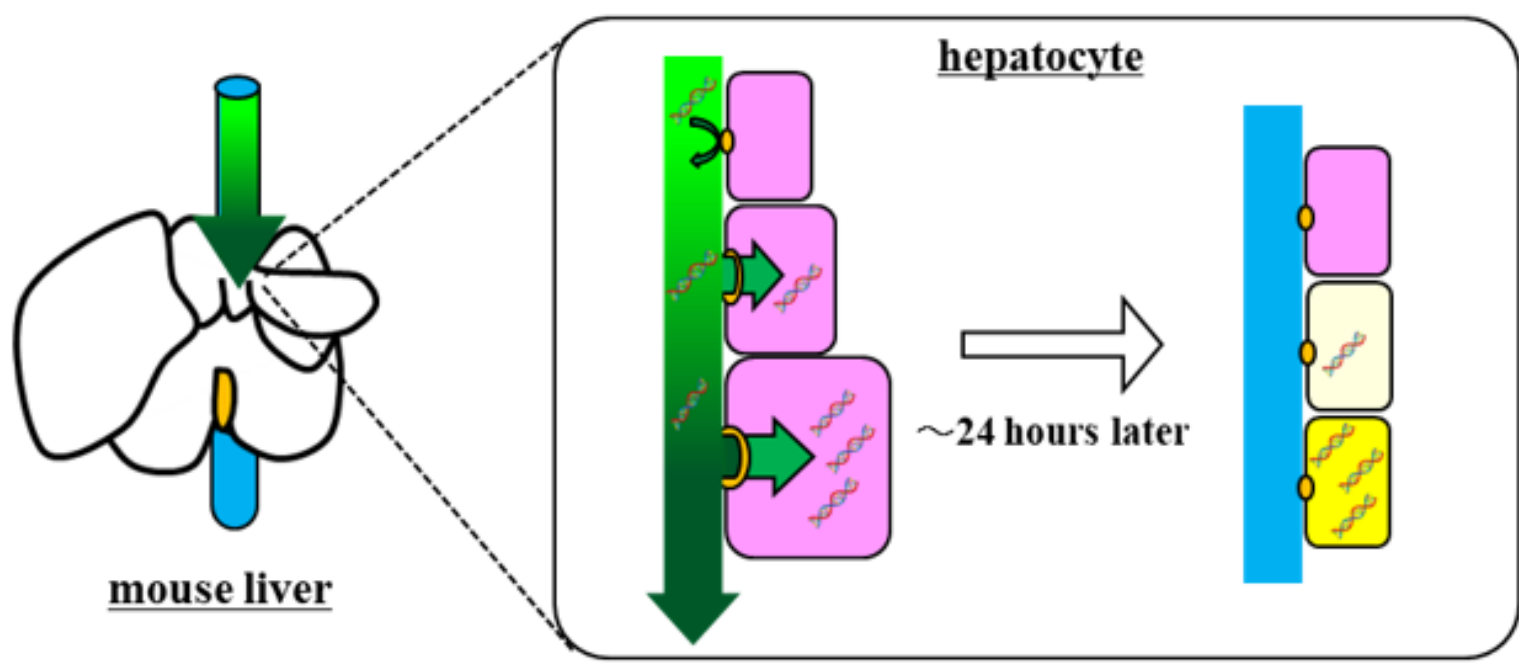

Figure 1 Simplified scheme explaining the hydrodynamics-based gene delivery (HGD) method. (a) When a large amount of a solution (green) containing nucleic acids (NAs) is injected rapidly and instantaneously into the tail-vein, the solution given intravenously stagnates once it reaches the heart (red). (b) Due to this stasis, the solution flows backward into the vena cava and the hepatic vein (blue). (c) The pores (orange) on the cell membrane of hepatocytes (peach) were generated by the pressure of the reflux of a large amount of solution, and the solution containing the NAs flowed into the hepatocytes. Since the pores are closed within a few minutes, the inflowing NAs remain inside the cells, and part of them reach the cell nucleus. Within $24 \mathrm{~h}$ after HGD, the swelling of cells is thought to be restored (yellow), having a large number of NAs, which appear to exhibit stronger transgene expression.

The principle of HGD relies on the mechanical force exerted by the rapid injection of a large volume of solution containing NAs (shown schematically in Figure 1). In brief, the volume $(\mathrm{mL})$ used for HGD was calculated as one-tenth of the body weight (g). For example, for a $20 \mathrm{~g}$ mouse, 2 $\mathrm{mL}$ of the solution is required. The injection was performed at a constant speed via the tail-vein and completed within 5-7s. The force created transient congestion in the right ventricle, allowing the solution to flow back into the hepatic vein, followed by the passage of the solution through the sinusoidal structure to the portal veins, allowing the force to generate transient pores in the 
hepatocyte cell membrane [54-56]. The transient pores disappeared naturally in a short time. While the pores exist, NAs present in the solution entered the hepatocytes and were trapped in the cells; part of them migrated into the nucleus, where they facilitate targeted gene expression. Besides, exogenous NAs are not susceptible to DNA degradation by DNase present in the blood because blood is transiently cleared away from the vessels due to a large amount of the solution and its rapid flow rate. Several transfected cells can be seen in the overall area of the liver; although successful gene delivery is also seen in other organs such as the lungs, heart, and kidneys, the extent is less than that in the liver. The major advantage of HGD is a lower risk of immune responses and oncogenesis. Specifically, naked DNA plasmids and saline do not exhibit any immunogenicity, or the potential for DNA integration, compared to the chemical compounds used in non-viral gene delivery methods [56].

Genome editing tools such as zinc-finger nucleases (ZFNs), transcription activator-like effector nucleases (TALENs), and the clustered regularly interspaced short palindromic repeats (CRISPR)/CRISPR-associated protein-9 nuclease (Cas9) (CRISPR/Cas9) have been successfully used to manipulate genomes with unprecedented precision [57]. In the field of human gene therapy, the feasibility of genome editing in primary human hematopoietic cells has been tested since the engineered cells have the potential to treat a variety of human genetic disorders [58]. For example, these studies include the prevention of human immunodeficiency virus type 1 (HIV-1) infection in hematopoietic cells after transfection with ZFNs [59] and targeted genome editing in acute lymphoblastic leukemia by TALENs [60].

Among these three genome editing tools, CRISPR/Cas9 is considered useful for performing genome editing in vivo and in vitro because it is simpler to design guide (g)RNAs and construct Cas9 endonuclease/gRNA complexes (called 'ribonucleoproteins [RNPs]') than ZNFs and TALENs [61], and is considered to be one of the most promising tools in the field of human gene therapy [62]. The target sequence recognized by RNPs must immediately precede a 5'-NGG protospacer adjacent motif (PAM) [63]. Once an RNP is incorporated into a cell, it introduces double-stranded breaks (DSB) at the target site of the host chromosome. These DSBs are then repaired by a process known as nonhomologous end-joining (NHEJ) [64], which often leads to insertion and/or deletion of nucleotides (indels). If an exogenously supplied repair template is present, gene addition or repair occurs through a homology-directed repair (HDR) mechanism [65]. This event is also called knock-in (KI). $\mathrm{KI}$ is generally known to be more difficult to complete than the induction of NHEJmediated indels. Furthermore, NHEJ occurs in non-dividing and dividing cells, but HDR occurs preferentially in dividing cells [66].

To date, there are several ways in which the two components (gRNA and Cas9) are delivered into a cell: one is in the form of plasmid DNA (i.e., all-in-one plasmid DNA carrying both gRNA and Cas9 genes), the second in the form of mRNA (for both gRNA and Cas9), and the third as RNP. As a result, CRISPR/Cas9 is now widely used for the manipulation of $\mathrm{GOI}$ in different cells and organisms $[67,68]$.

Notably, AAV vectors enable long-term GOI expression, exhibit tissue tropism across 13 serotypes, and can transduce both dividing and non-dividing cells [69]. Unlike other viral vectors, rAAV vectors carry a GOI of only about $4.7 \mathrm{~kb}$ in size [69], which may partly limit their application. Ran et al. [70] described a new version of Cas9, called Staphylococcus aureus-derived Cas9 (saCas9). This version is approximately $1 \mathrm{~kb}$ shorter than Streptococcus pyogenes-derived Cas 9 
(spCas9), the more widely used Cas9. saCas9 has Cas9 activity similar to that of spCas9. Therefore, it is possible to create rAAV vectors carrying both saCas9 and gRNA in the form of an all-in-one vector.

As shown in Table 1, studies on genetic manipulation of the hepatocyte genome employ the CRISPR/Cas9 system through which target-specific mutations or insertion of GOI can be achieved.

In the following sections, several examples of introducing genome editing components via tailvein injection are explored in detail.

\section{Generation of Mice with Liver Cancer}

The CRISPR/Cas9 system enables the creation of mutations (i.e., indels, translocation, and rearrangement) involving target genes, which are thought to be essential for hepatic function. If such a locus is disrupted by the HGD coupled with the CRISPR/Cas9 system, the creation of a mouse strain with hepatic disorders is highly expected, and the resulting mice can be used as liver disease models. In the following sections, several papers related to this subject, particularly involving liver tumorigenesis, are presented.

In 2014, Xue et al. [25] first showed that HGD of CRISPR/Cas9 components (targeted to $p 53$ and phosphatase and tensin homolog deleted from chromosome 10 [Pten] genes) into adult mice could yield cancer-related phenotypes involving the liver after treatment with carbon tetrachloride $\left(\mathrm{CCl}_{4}\right)$, an agent widely used to induce liver injury in rodents. They showed that HGD can transport plasmid DNA to approximately $20 \%$ of hepatocytes, and multifocal tumors were observed in the adult mouse liver. Most importantly, this method bypasses the need to create germline Tg offspring carrying targeted mutations. Therefore, HGD coupled with the CRISPR/Cas 9 system is an alternative to study the mechanisms involved in liver tumorigenesis.

Liu et al. [40] attempted to induce liver tumorigenesis in hepatitis B virus (HBV)-Tg mice by simultaneously introducing $p 53$ and Pten mutations through HGD coupled with the CRISPR/Cas9 system. As expected, these treated mice exhibited somatic induction of $p 53$ and Pten mutations in the liver, leading to the induction of hepatocellular carcinoma (HCC) as early as four months postinjection. Therefore, this study appears to present a rapid and convenient method for generating mouse models with liver cancer and HBV infection.

Both Pten and neuroblastoma RAS viral oncogene homolog (Nras) are downstream mediators of receptor tyrosine kinase activation that play an important role in controlling cell survival and proliferation. Gao and Liu [41] examined whether and how Pten loses cross-talk with Nras activation in driving liver tumorigenesis in mice. Somatic disruption of Pten and overexpression of Nras in out-bred immunocompetent CD-1 mice after HGD of a solution containing Sleeping Beauty (SB) transposon-based plasmid carrying Nras transgene and the plasmid potentially conferring expression of Cas9 and gRNA (targeted to Pten) caused HCC, whereas individual gene manipulation failed. Tumor development was associated with liver fibrosis, hyperlipidemia, hepatic deposition of lipid droplets and glycogen, and hepatomegaly. These findings demonstrated that Pten disruption was synergized by Nras overexpression in driving hepatocyte malignant transformation. 


\section{Rat Liver Disease Models}

Pten is known to be an anti-oncogenic protein which, when defective, causes nonalcoholic fatty liver disease (NAFLD) [71]. Mice with Pten KO phenotype are also known to exhibit NAFLD [72]. Yu et al. [43] attempted to create a NAFLD model in rats via intravenous injection of a pX330-based all-in-one plasmid conferring expression of both Cas9 and gRNA (targeted to Pten). They injected $10 \mathrm{~mL}$ of saline water containing various concentrations of plasmid DNA $(75,150$, and $300 \mu \mathrm{g} / 100$ g) into male Sprague-Dawley (SD) rats via HGD. Nine weeks after injection, the high-dose group (300 $\mu \mathrm{g} / 100 \mathrm{~g}$ ) showed severe lipid deposition and substantial knockdown of Pten. These findings suggest the usefulness of the HGD and CRISPR/Cas9 systems in manipulating the rat liver genome to construct animal models with liver disease. In other words, the HGD and CRISPR/Cas9 systems are useful for the manipulation of rodent genomes.

\section{Correction of Genetic Diseases In Vivo}

As mentioned earlier, HGD enables efficient in vivo gene delivery to the liver. Therefore, it is reasonable to consider that HGD might be useful for evaluating the therapeutic potential of the CRISPR/Cas9 system when liver disease model mice are used in proof-of-principle experiments. In the following, several examples are presented.

In 2014, Yin et al. [26] first demonstrated that intravenous delivery of CRISPR/Cas9 reagents to adult mammalian organs can successfully correct genetic disease-related genes. For this, they used a mouse model of the human disease hereditary tyrosinemia (called Fahmut/mut mice), a fatal genetic disease caused by a mutation in the gene Fah coding for fumarylacetoacetate hydrolase, the final enzyme in the tyrosine catabolic pathway. Fah deficiency causes the accumulation of toxic metabolites, such as fumarylacetoacetate in hepatocytes, resulting in severe liver damage, and leading to weight loss. This mouse model harbors a $G \rightarrow A$ mRNA splicing mutation involving the last nucleotide of Fah exon 8. To edit the endogenous Fah locus, they intravenously introduced an all-in-one plasmid that potentially co-expresses gRNA (targeted to Fah) and Cas9, with a single-stranded DNA (ssDNA) donor carrying the wild-type G nucleotide to facilitate homologous recombination (HR) and correct the mutation using HGD. They observed the wildtype Fah protein in $\sim 1 / 250$ liver cells after HGD, and that expansion of Fah-positive hepatocytes rescued the bodyweight loss phenotype. These findings indicate that CRISPR/Cas9-mediated genome editing is possible in adult animals, and suggests the potential for correction of human genetic diseases.

Huai et al. [47] used the CRISPR/Cas9 system for gene correction in an in-house factor IX (F9) mutant hemophilia B (HB) mouse model, which has an 8-bp deletion in the 8th exon of the mouse F9 gene. They intravenously injected an all-in-one plasmid carrying the Cas9 gene, gRNA, and donor DNA into the HB model mice using HGD in an attempt to correct the mutation. Consequently, $62.5 \%$ of the HGD-treated mice presented a detectable gene correction ( $>1 \%)$ in the F9 alleles of hepatocytes, which was sufficient to remit the coagulation deficiency.

Mucopolysaccharidosis type I (MPS I) is a multisystemic disorder caused by alpha-L-iduronidase (IDUA) deficiency, which leads to intracellular accumulation of glycosaminoglycans (GAGs). Schuh et al. [47] used cationic liposomes (DOPE/DOTAP/DSPE-PEG) carrying the CRISPR/Cas9 plasmid and a donor vector for in vitro and in vivo MPS I gene editing. HGD used liposomal complexes in 
the superficial temporal vein of newborn mice (2-3 days old) MPS I C57BL/6 mice, leading to a significant increase in serum IDUA levels for up to six months. In this case, a single injection volume contained $40 \mu \mathrm{g}$ of DNA corresponding to $10 \%$ of bodyweight. In mice, the introduced plasmid was detected after HGD in the lungs and heart, corroborating the results of increased IDUA activity and decreased GAG storage, especially in these tissues. They concluded that IDUA production in multiple organs has a significant beneficial effect on the MPS I disease characteristics, which may be helpful for gene therapy in patients with a genetic disorder Hurler syndrome.

Hemophilia A (HA) is a bleeding disorder resulting from factor VIII (F8) mutations. It can only be cured using gene therapy. A promising strategy is precise CRISPR/Cas9-mediated insertion of F8 in hepatocytes at highly expressed gene loci, such as albumin $(A / b)$. Unfortunately, the precise in vivo integration efficiency of long inserts is very low ( 0.1\%). Zhang et al. [49] reported that the use of a double-cut donor led to a 10- to 20-fold increase in liver editing efficiency, thereby completely reconstituting serum $\mathrm{F} 8$ activity in a mouse model of HA after HGD using a CRISPR/Cas9 plasmid targeted to $A l b$, and a B domain-deleted (BDD) F8 construct (hereinafter termed 'BDDF8'). A follow-up of 100 mice over one year showed no adverse effects.

Similar reports were also provided by other groups independently from Zhang et al. [49]. Chen et al. [50] described a CRISPR/Cas9-based in vivo genome editing method, combined with NHEJ, enabling permanent chromosomal integration of a modified human BDDF8 at the Alb locus in liver cells. They performed the conventional tail-vein injection using two vectors, rAAV 8 carrying saCas 9 and gRNA (targeting $A / b$ intron 13) and rAAV8-BDDF8. This resulted in BDDF8 insertion at the $A / b$ locus and F8 protein expression in the liver of vector-treated HA model mice. BDDF8 was expressed in liver cells as functional human F8, leading to increased plasma levels of F8 and restoration of blood clotting properties for at least seven months, with no detectable liver toxicity.

Precise correction of disease-causing mutations requires the repair of Cas9-induced doublestranded DNA (dsDNA) breaks by HDR mechanisms, which are highly inefficient in non-dividing cells [66]. Recently, a new system, called 'CRISPR-Cas-associated base editing' was developed that enables conversion of C-G to T-A base pairs and vice versa, independent of dsDNA break formation and HDR [73-75]. Villiger et al. [53] corrected the disease phenotype in adult phenylalanine hydroxylase $(P a h)^{\text {enu2 }}$ mice, a model for the human autosomal recessive liver disease, phenylketonuria (PKU), using one of the CRISPR-Cas-associated base editors, called 'intein-split base editor'. This editor allows the splitting of the fusion protein into two parts, thereby circumventing the limited packaging capacity of AAV vectors. Conventional tail-vein injection of AAV-base editing agents resulted in $\mathrm{Pah}^{\text {enu2 }}$ gene correction rates that restored physiological blood phenylalanine levels below $120 \mu \mathrm{mol} / \mathrm{L}$, with the restoration of phenylalanine hydroxylase enzyme activity. These findings suggest the feasibility of using AAV-mediated delivery of base-editing agents for the treatment of genetic diseases in vivo. Intrathecal injection of rAAV particles was also used to correct the disease phenotype in a mouse model of amyotrophic lateral sclerosis (ALS) caused by mutations in the superoxide dismutase 1 (SOD1) gene [76]. This treatment resulted in prolonged survival and marked delay in the progression of disease in the ALS model mice.

Song et al. [52] recently demonstrated that the $A>G$ splice-site mutation in Fah associated with hereditary tyrosinemia is curable by the adenine base editor ( $A B E)$ system, one of the base editor techniques enabling the conversion of A-T base pairs to G-C base pairs [74]. When Fahmutmut mice were subjected to HGD of a solution containing $A B E$, splicing was partially restored, along with the 
generation of Fah-positive hepatocytes in the liver and rescued weight loss. This indicates that correction of point mutations without supplying a DNA-repair template is possible. These findings suggest that $A B E$ can be used for the correction of genetic diseases in adult animals.

Anzalone et al. [77] developed a new system, called 'prime editing,' enabling targeted insertions, deletions, and base-to-base conversions without the need for DSBs or donor DNA templates. This method uses a fusion protein consisting of a catalytically impaired Cas9 endonuclease fused to an engineered reverse transcriptase enzyme and a prime editing gRNA (pegRNA) capable of identifying the target site and providing new genetic information to replace the target DNA nucleotides. Anzalone et al. [77] demonstrated that applying prime editing to human HEK293T cells to remove $4 \mathrm{bp}$ in the hexosaminidase $\mathrm{A}$ (HEXA) gene resulted in the correction of the most common mutations that causes Tay-Sachs disease. According to Anzalone et al. [77], prime editors exhibited higher or similar efficiency as Cas9-initiated HDR, with much lower indels and off-target activity. Prime editing may be a powerful tool to correct mutations in liver-related disorders, although the technology itself appears to be at an early stage of development.

\section{Genome-Editing-Based Treatment for Viral Infections}

Chronic infections with HBV and hepatitis C virus (HCV) cause liver cirrhosis and hepatocellular carcinoma, and remains a serious health problem worldwide. Current therapies for infections have limitations, and improved efficacy is necessary to prevent complications in carriers of the relevant viruses [78]. The persistence of replication intermediates comprising covalently closed circular DNA (ccCDNA) in the liver cell nuclei causes sustained HBV infection and represents a major barrier for the current antiviral therapy. Major treatments for HBV infection include the use of interferon$\alpha$ and nucleotide analogs, but they cannot eradicate cccDNA [78]. Several studies have reported good efficacy when employing CRISPR/Cas9 technologies to disable HBV replication in vitro and in vivo.

For example, Dong et al. [29] demonstrated that the CRISPR/Cas9 system can be used to target the HBV genome and efficiently inhibit HBV infection. Intravenous injection of an all-in-one plasmid conferring expression of both gRNA and Cas9 into a new mouse model carrying HBV cccDNA resulted in low levels of cccDNA and HBV protein. These findings indicate that the designed CRISPR/Cas9 system can accurately and efficiently target HBV cccDNA and inhibit HBV replication, and suggest that this system may be used as a novel therapeutic strategy against chronic HBV infection.

Zhu et al. [31] applied the CRISPR/Cas9 system to target and delete the conserved regions of the HBV genome. HGD-based introduction of an all-in-one plasmid conferring expression of both gRNA and Cas9 into a mouse model of HBV, termed hepatitis B virus Tg mice (M-TgHBV), resulted in decreased levels of hepatitis $B$ virus antigen ( $\mathrm{HBsAg}$ ) in the serum and liver. These findings indicate that the designed CRISPR/Cas9 system can induce anti-HBV effects, and may represent a novel antiviral agent against chronic HBV infection.

The CRISPR/Cas9 system is also applicable to eradicate integrated HIV-1 DNA. Kaminski et al. [33] intravenously injected a rAAV9 vector capable of expressing both saCas9 and gRNA, called rAAV9:saCas9/gRNA, to eradicate integrated HIV-1 DNA in vivo. Kaminski et al. [33] observed the cleavage of integrated HIV-1 DNA in the spleen, liver, heart, lung, and kidney as well as in 
circulating lymphocytes. Retro-orbital inoculation of rAAV9:saCas9/gRNA in Tg rats carrying HIV-1 DNA eliminated a targeted segment of viral DNA, and substantially decreased the level of viral gene expression in circulating blood lymphocytes. According to Kaminski et al. [33], this represents the first in vivo eradication of integrated copies of HIV-1 DNA by CRISPR/Cas9 coupled with a rAAV9 vector.

\section{New Methodology}

CRISPR/Cas9-based genome engineering technology coupled with HGD has also opened a new means to develop novel methods to manipulate the hepatocyte genome. These combined technologies have led to the simplification and acceleration of exploratory research concerning physiological activity and gene functions in the murine liver [79]. Below, some examples will be presented.

Sakurai et al. [34, 35] performed convenient targeting in mouse liver using Tg mice expressing a systemic Cas9 transgene (called 'sCAT' mouse). They injected gRNA targeted to the Alb gene plus an enhanced green fluorescent protein (EGFP) expression plasmid (monitoring successful transfection of hepatocytes) using the HGD system into the SCAT mice. They collected EGFPexpressing or non-expressing hepatocytes from the HGD-treated liver tissue and identified that approximately $1 / 1000$ cells were successfully transfected, and almost all of these fluorescent cells were genome-edited single hepatocytes. They provided detailed protocols for the collection and analysis of single genome-edited hepatocytes, which will be helpful for many types of hepatocyte functional studies.

Song et al. [39] performed a genome-wide screen to identify suppressors of liver tumor formation in mice, using CRISPR-mediated genome editing coupled with HGD. Mice underwent HGD of plasmids encoding $M y c$ and sgRNA/Cas9 designed to disrupt the candidate tumor suppressor $p 53$. Next, the gene expression profiles of liver cells with and without the tumor suppressor gene disrupted by sgRNA/Cas9 were compared. Genes found to be up-regulated after tumor suppressor loss were examined in liver cancer cell lines; their expression was knocked down using small hairpin RNAs, and tumor growth was examined in nude mice. As a result, four candidate liver tumor suppressor genes ( $N f 1$, Plxnb1, Flrt2, and B9d1) were identified, all of which were not previously associated with liver cancer.

Pankowicz et al. [46] developed a novel liver-specific KO system [called somatic liver knockout (SLiK)] using Fah ${ }^{\text {mut/mut }}$ mice, a model for hereditary tyrosinemia. Fah ${ }^{\text {mut/mut }}$ mice were subjected to HGD of an all-in-one plasmid conferring expression of both Cas9 and gRNA [designed to excise exons of the 4-hydroxyphenylpyruvate dioxygenase $(\mathrm{Hpd})$ gene]. Hpd-edited hepatocytes can survive in Fahut/mut mice. Using this principle, plasmids that target Hpd and a separate GOI can therefore be used to rapidly generate mice with liver-specific deletion of nearly any gene. They used this system to create mice with liver-specific KO of argininosuccinate lyase (ASL), which

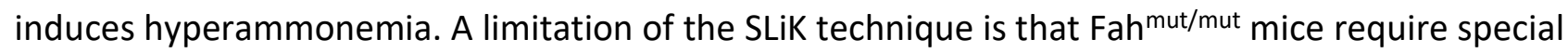
care to avoid the hepatotoxicity caused by Fah deficiency through the addition of nitisinone, an inhibitor of HPD. Therefore, upon withdrawal of nitisinone, only Hpd-deficient hepatocytes (in which a separate $\mathrm{GOI}$ is also disrupted) will clonally expand with the same genetic modifications. 


\section{Targeted to Fetal Liver}

Transplacental transfer of the plasmid DNA constructs after systemic injection via the tail-vein of pregnant mice was reported as a noninvasive and convenient method for the transfection of fetal tissues [80]. After transplacental transport, the administered NAs that reached the fetal circulation and fetal tissues/cells are efficiently transfected. This novel approach is hereinafter termed 'transplacental gene delivery (TPGD)'. To the best of our knowledge, there have been 14 reports concerning TPGD to date [81]. These findings prompted us to suppose that CRISPR/Cas9mediated genome editing is possible in fetal tissues/cells when a plasmid DNA capable of expressing both Cas9 and gRNA is intravenously applied to pregnant female mice.

Recently, Nakamura et al. [82], for the first time, achieved CRISPR/Cas9-mediated mutations in a target locus in embryonic cells using this technique. They intravenously injected a solution containing an all-in-one plasmid (pCGSap1-EGFP) complexed with FuGENE6 (a lipid transfection accelerating reagent) to pregnant mice on an embryonic day (E)12.5 of pregnancy to elicit CRISPR/Cas9-mediated mutations in a target locus in fetal cardiac cells because, in our previous study [83], the fetal heart was the most extensively transfected tissue in TPGD. Pregnant females were successfully mated with Tg males with EGFP transgenes in a homozygous manner. Therefore, all of the fetuses in these pregnant females should express EGFP systemically since they are heterozygous $(\mathrm{Tg} /+)$ for the transgene. pCGSap1-EGFP can confer an expression of both Cas9 and gRNA targeted to EGFP CDNA. Hence, fetal delivery of the CRISPR system targeted to the EGFP will cause reduced expression of EGFP as a result of the genome editing of the EGFP genomic sequence. According to Nakamura et al. [82], of the 24 fetuses isolated from three pregnant females two days after gene delivery, three were found to have reduced cardiac fluorescence. Dissection of the fetal hearts revealed the presence of a transgene construct (Cas9 gene). Furthermore, all three samples exhibited mutations at the target locus, although normal cells were also present. This novel approach has the potential to manipulate the fetal genome through simple tail-vein administration of CRISPR/Cas9 components in a noninvasive manner. Therefore, this technology has been re-named 'TPGD for acquiring genome-edited fetuses (TPGD-GEF)'.

Nakamura et al. [84] extended TPGD-GEF and showed that HGD of plasmid pCGSap1-MHC (targeted to endogenous myosin heavy chain $\alpha(\mathrm{MHC} \alpha)$ gene) in pregnant females on E9.5 resulted in the generation of genome-edited fetuses with an efficiency of $4.16 \%$ (Figure 2). Molecular analysis revealed that the mode of genome editing seen in these fetuses was mosaic (i.e., a mixture of genome-edited and non-genome edited cells). Furthermore, this mosaicism is found not only in the fetal heart but also in other fetal organs. Therefore, there exists the possibility of genome editing in the fetal liver, when TPGD-GEF coupled with HGD, is performed at E9.5 of pregnancy. 


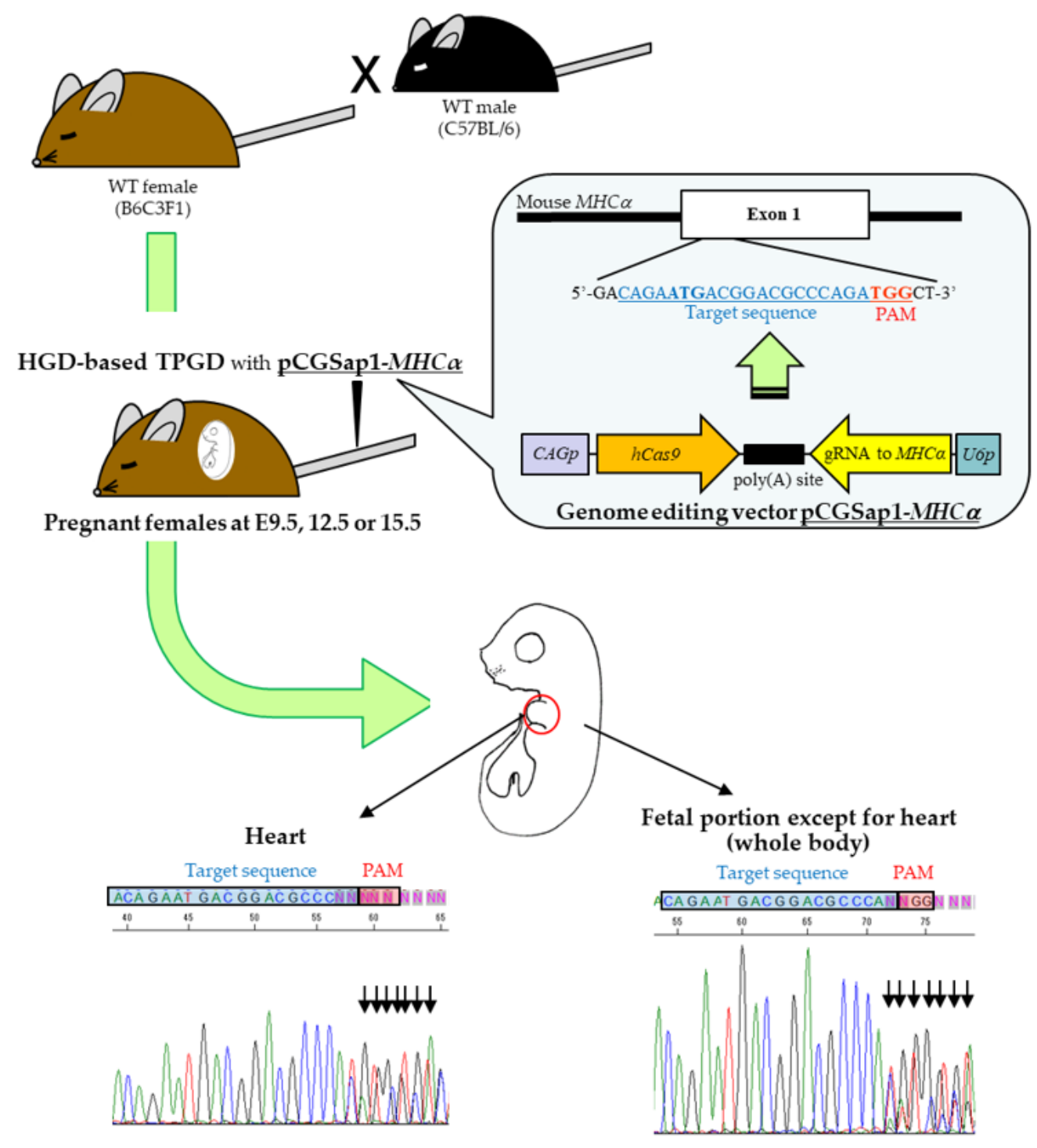

Figure 2 Hydrodynamics-based gene delivery (HGD)-based transplacental gene delivery for acquiring genome-edited fetuses (TPGD-GEF) using all-in-one vector pCGSap1$\mathrm{MHC \alpha}$ [84]. First, B6C3F1 females were mated to C57BL/6 male mice. On the day, when females were confirmed to have copulatory plugs in their vaginas, 12:00 was defined as E (embryonic day) 0.5 of pregnancy. On E9.5, E12.5, or E15.5 of pregnancy, a solution containing pCGSap1-MHC $\alpha$ was intravenously administered to the pregnant females. Two days after HGD, the fetuses were dissected to expose the fetal heart and other parts designated as the 'whole body.' These samples were then subjected to molecular biological analyses for the detection of mutations at the $M H C \alpha$ locus. Only samples derived from HGD-based TPGD-GEF on E9.5 were identified as those with mutated $M H C \alpha$. Overlapping electrophoretograms (indicated by arrows) are notable immediately upstream of the PAM, indicating the presence of genome-edited and unedited sequences. This mode of mutations is called 'mosaic.' Abbreviations: CAG, chicken $\beta$-actin-based promoter; gRNA, guide RNA; hCas9, humanized Cas9 gene; $M H C \alpha$, myosin heavy-chain $\alpha$ gene; PAM, protospacer adjacent motif; $U 6$, human U6 promoter; WT, wild-type. 


\section{Other Issues to be Addressed}

According to Yin et al. [26], when HGD is performed, the efficiency of transfection in hepatocytes is $\sim 1 / 250$. A similar efficiency ( 1/1000) was also reported by Sakurai et al. [34, 35], who performed molecular biological analysis on individual hepatocytes and demonstrated that almost all transfected cells were successfully genome-edited. This suggests that CRISPR/Cas 9 reagents provided through HGD show highly efficient genome editing in hepatocytes.

As previously mentioned, HGD requires the injection of a large volume of solution within a short period (within 5-7 s), which may be deleterious when this technology is applied to humans. Notably, Suda et al. [85] reported that fluid overload in the systemic circulation induces irregular cardiac function, leading to transient heart failure. To avoid such possible side effects, the feasibility of local administration with the aid of a catheter is now considered a safer approach instead of systemic administration to achieve gene delivery to large animals [86]. However, in mice, there are no reports that HGD is harmful to the behavior of treated mice. As for the effects on fetal development, Nakamura et al. [84] reported that, in the case of mice used for HGD, there was no appreciable damage to fetuses or the pregnant mother. In this regard, HGD appears to be a safe tool, enabling efficient delivery of NAs to internal organs, including the liver, in mice.

\section{Concluding Remarks}

HGD is a convenient tool to transfect rodent hepatocytes with non-viral DNA with relatively high efficiency. The CRISPR/Cas9 system is one of the recently developed genome editing technologies, which enables mutation induction or gene correction of a target gene. This genome editing reagent can be easily introduced into the bloodstream via HGD and, consequently, transfected hepatocytes undergo genome-editing with high efficiency. Using this approach, it is possible to obtain rapid information regarding the consequences elicited after in vivo manipulation of the target genes than using the previous systems (based on transgenesis), which is laborious, costly, and time-consuming. It is possible to create animal models with liver disease, or cure hereditary disorders in the liver within a short period, which will help develop and establish strategies for gene therapy. Furthermore, with HGD coupled with CRISPR/Cas9, new methodologies have emerged, as illustrated by gene screening of new genes related to oncogenesis, a novel liver-specific KO system called somatic liver KO (SLiK), and application of newly developed genome editing systems, as illustrated by $A B E$ and prime editing. Manipulation of the fetal genome is also possible with HGD-based TPGD-GEF. Further progression of hepatocyte genome manipulation, based on the simple gene delivery system termed HGD, is highly anticipated.

Notably, the HGD method is difficult to apply in humans as it introduces a large volume of solution into the body. The main possible concern is that rapid injection of such a huge volume of the solution may overload the systemic circulation, followed by induction of irregular cardiac function leading to transient heart failure [85]. To avoid this event, Kamimura et al. [86] suggested administering the solution with the aid of a catheter. Although these efforts are still in progress, the results obtained may be beneficial for the development of human gene therapy. 


\section{Acknowledgments}

This study was partly supported by JSPS KAKENHI (no. 19 H03152 for S.N.).

\section{Author Contributions}

S.N. designed and wrote the manuscript. N.A. created figures and summarized the references. M.I. critically revised the manuscript. M.S. wrote the manuscript and revised the manuscript.

\section{Competing Interests}

The authors have declared that no competing interests exist.

\section{References}

1. Miao X. Recent advances in the development of new transgenic animal technology. Cell Mol Life Sci. 2013; 70: 815-828.

2. Ohtsuka M, Miura H, Sato M, Kimura M, Inoko H, Gurumurthy CB. PITT: Pronuclear injectionbased targeted transgenesis, a reliable transgene expression method in mice. Exp Anim. 2012; 61: 489-502.

3. Iyer M, Wu L, Carey M, Wang $Y$, Smallwood A, Gambhir SS. Two-step transcriptional amplification as a method for imaging reporter gene expression using weak promoters. Proc Natl Acad Sci U S A. 2001; 98: 14595-14600.

4. Nettelbeck DM, Jerome $V$, Muller R. A strategy for enhancing the transcriptional activity of weak cell type-specific promoters. Gene Ther. 1998; 5: 1656-1664.

5. Nakamura S, Watanabe S, Ohtsuka M, Maehara T, Ishihara M, Yokomine $T$, et al. Cre-loxP system as a versatile tool for conferring increased levels of tissue-specific gene expression from a weak promoter. Mol Reprod Dev. 2008; 75: 1085-1093.

6. Wu GY, Wu CH. Receptor-mediated gene delivery and expression in vivo. J Biol Chem. 1988; 263: 14621-14624.

7. Wolff JA, Malone RW, Williams P, Chong W, Acsadi G, Jani A, et al. Direct gene transfer into mouse muscle in vivo. Science. 1990; 247: 1465-1468.

8. Alino SF, Crespo J, Bobadilla M, Lejarreta M, Blaya C, Crespo A. Expression of human alpha 1antitrypsin in mouse after in vivo gene transfer to hepatocytes by small liposomes. Biochem Biophys Res Commun. 1994; 204: 1023-1030.

9. Dankó I, Jia Z, Zhang G. Nonviral gene transfer into liver and muscle for treatment of hyperbilirubinemia in the gunn rat. Hum Gene Ther. 2004; 15: 1279-1286.

10. Saridey SK, Liu L, Doherty JE, Kaja A, Galvan DL, Fletcher BS, et al. PiggyBac transposon-based inducible gene expression in vivo after somatic cell gene transfer. Mol Ther. 2009; 17: 21152120.

11. Woodard LE, Cheng J, Welch RC, Williams FM, Luo W, Gewin LS, et al. Kidney-specific transposon-mediated gene transfer in vivo. Sci Rep. 2017; 7: 44904.

12. Nakamura S, Ishihara M, Watanabe S, Ando N, Ohtsuka M, Sato M. Intravenous delivery of piggyBac transposons as a useful tool for liver-specific gene-switching. Int J Mol Sci. 2018; 19: 3452. 
13. Fraser MJ, Cary L, Boonvisudhi K, Wang HG. Assay for movement of Lepidopteran transposon IFP2 in insect cells using a baculovirus genome as a target DNA. Virology. 1995; 211: 397-407.

14. Sato M, Inada E, Saitoh I, Watanabe S, Nakamura S. piggyBac-based non-viral in vivo gene delivery useful for production of genetically modified animals and organs. Pharmaceutics. 2020; 12: 277.

15. Aravalli RN, Belcher JD, Steer CJ. Liver-targeted gene therapy: Approaches and challenges. Liver Transpl. 2015; 21: 718-737.

16. Jaffe HA, Danel C, Longenecker G, Metzger M, Setoguchi Y, Rosenfeld MA, et al. Adenovirusmediated in vivo gene transfer and expression in normal rat liver. Nat Genet. 1992; 1: 372-378.

17. Kafri T, Blömer U, Peterson DA, Gage FH, Verma IM. Sustained expression of genes delivered directly into the liver and muscle by lentiviral vectors. Nat Genet. 1997; 17: 314-317.

18. VandenDriessche T, Thorrez L, Naldini L, Follenzi A, Moons L, Berneman Z, et al. Lentiviral vectors containing the human immunodeficiency virus type- 1 central polypurine tract can efficiently transduce nondividing hepatocytes and antigen-presenting cells in vivo. Blood. 2002; 100: 813-822.

19. Snyder RO, Miao C, Meuse L, Tubb J, Donahue BA, Lin HF, et al. Correction of hemophilia B in canine and murine models using recombinant adeno-associated viral vectors. Nat Med. 1999; 5: 64-70.

20. Xu L, Daly T, Gao C, Flotte TR, Song S, Byrne BJ, et al. CMV- $\beta$-actin promoter directs higher expression from an adeno-associated viral vector in the liver than the cytomegalovirus or elongation factor 1 alpha promoter and results in therapeutic levels of human factor $\mathrm{X}$ in mice. Hum Gene Ther. 2001; 12: 563-573.

21. Nathwani AC, Davidoff AM, Hanawa H, Hu Y, Hoffer FA, Nikanorov A, et al. Sustained highlevel expression of human factor IX ( $\mathrm{hFIX)} \mathrm{after} \mathrm{liver-targeted} \mathrm{delivery} \mathrm{of} \mathrm{recombinant} \mathrm{adeno-}$ associated virus encoding the hFIX gene in rhesus macaques. Blood. 2002; 100: 1662-1669.

22. Liu F, Song $Y$, Liu D. Hydrodynamics-based transfection in animals by systemic administration of plasmid DNA. Gene Ther. 1999; 6: 1258-1266.

23. Zhang G, Budker V, Wolff JA. High levels of foreign gene expression in hepatocytes after tail vein injections of naked plasmid DNA. Hum Gene Ther. 1999; 10: 1735-1737.

24. Zhang G, Song YK, Liu D. Long-term expression of human alpha1-antitrypsin gene in mouse liver achieved by intravenous administration of plasmid DNA using a hydrodynamics-based procedure. Gene Ther. 2000; 7: 1344-1349.

25. Xue W, Chen SD, Yin H, Tammela T, Papagiannakopoulos T, Joshi NS, et al. CRISPR-mediated direct mutation of cancer genes in the mouse liver. Nature. 2014; 514: 380-384.

26. Yin $H$, Xue W, Chen S, Bogorad RL, Benedetti E, Grompe M, et al. Genome editing with Cas9 in adult mice corrects a disease mutation and phenotype. Nat Biotechnol. 2014; 32: 551-553.

27. Wang D, Mou H, Li S, Li Y, Hough S, Tran K, et al. Adenovirus-mediated somatic genome editing of Pten by CRISPR/Cas9 in mouse liver in spite of Cas9-specific immune responses. Hum Gene Ther. 2015; 26: 432-442.

28. Weber J, Ollinger R, Friedrich M, Ehmer U, Barenboim M, Steiger K, et al. CRISPR/Cas9 somatic multiplex-mutagenesis for high-throughput functional cancer genomics in mice. Proc Natl Acad Sci U S A. 2015; 112: 13982-13987.

29. Dong C, Qu L, Wang H, Wei L, Dong Y, Xiong S. Targeting hepatitis B virus cccDNA by CRISPR/Cas9 nuclease efficiently inhibits viral replication. Antiviral Res. 2015; 118: 110-117. 
30. Guan Y, Ma YL, Li Q, Sun ZL, Ma L, Wu LJ, et al. CRISPR/Cas9-mediated somatic correction of a novel coagulator factor IX gene mutation ameliorates hemophilia in mouse. EMBO Mol Med. 2016; 8: 477-488.

31. Zhu W, Xie K, Xu Y, Wang L, Chen K, Zhang L, et al. CRISPR/Cas9 produces anti-hepatitis B virus effect in hepatoma cells and transgenic mouse. Virus Res. 2016; 217: 125-132.

32. Li H, Sheng C, Liu HB, Liu GZ, Du XY, Du J, et al. An effective molecular target site in hepatitis B virus $S$ gene for Cas9 cleavage and mutational inactivation. Int J Biol Sci. 2016; 12: 1104-1113.

33. Kaminski R, Bella R, Yin C, Otte J, Ferrante P, Gendelman HE, et al. Excision of HIV-1 DNA by gene editing: A proof-of-concept in vivo study. Gene Ther. 2016; 23: 690-695.

34. Sakurai T, Kamiyoshi A, Kawate $H$, Mori $C$, Watanabe $S$, Tanaka $M$, et al. A non-inheritable maternal Cas9-based multiple-gene editing system in mice. Sci Rep. 2016; 6: 20011.

35. Sakurai T, Kamiyoshi A, Ohtsuka M, Gurumurthy CB, Sato $M$, Shindo T. Isolation and analysis of a genome-edited single-hepatocyte from a Cas9 transgenic mouse line. Methods Mol Biol. 2019; 1874: 257-271.

36. Xu CL, Qi XL, Du XG, Zou HY, Gao F, Feng T, et al. piggyBac mediates efficient in vivo CRISPR library screening for tumorigenesis in mice. Proc Natl Acad Sci U S A. 2017; 114: 722-727.

37. Engelholm LH, Riaz A, Serra D, Dagnaes-Hansen F, Johansen JV, Santoni-Rugiu E, et al. CRISPR/Cas9 engineering of adult mouse liver demonstrates that the Dnajb1-Prkaca gene fusion is sufficient to induce tumors resembling fibrolamellar hepatocellular carcinoma. Gastroenterology. 2017; 153: 1662-1673.

38. Kastenhuber ER, Lalazar G, Houlihan SL, Tschaharganeh DF, Baslan T, Chen CC, et al. DNAJB1PRKACA fusion kinase interacts with $\beta$-catenin and the liver regenerative response to drive fibrolamellar hepatocellular carcinoma. Proc Natl Acad Sci U S A. 2017; 114: 13076-13084.

39. Song CQ, Li YX, Mou HW, Moore J, Park A, Pomyen Y, et al. Genome-wide CRISPR screen identifies regulators of mitogen-activated protein kinase as suppressors of liver tumors in mice. Gastroenterology. 2017; 152: 1161-1173.

40. Liu Y, Qi X, Zeng Z, Wang L, Wang J, Zhang T, et al. CRISPR/Cas9-mediated p53 and Pten dual mutation accelerates hepatocarcinogenesis in adult hepatitis $B$ virus transgenic mice. Sci Rep. 2017; 7: 2796.

41. Gao M, Liu D. CRISPR/Cas9-based Pten knock-out and Sleeping Beauty Transposon-mediated Nras knock-in induces hepatocellular carcinoma and hepatic lipid accumulation in mice. Cancer Biol Ther. 2017; 18: 505-512.

42. Huai C, Jia C, Sun RL, Xu PP, Min TS, Wang QH, et al. CRISPR/Cas9-mediated somatic and germline gene correction to restore hemostasis in hemophilia B mice. Hum Genet. 2017; 136: 875-883.

43. Yu Q, Tan RZ, Gan Q, Zhong X, Wang YQ, Zhou J, et al. A novel rat model of nonalcoholic fatty liver disease constructed through CRISPR/Cas-based hydrodynamic injection. Mol Biotechnol. 2017; 59: 365-373.

44. Yao X, Wang X, Liu JL, Hu XD, Shi LY, Shen XW, et al. CRISPR/Cas9-mediated precise targeted integration in vivo using a double cut donor with short homology arms. EBioMedicine. 2017; 20: 19-26.

45. Wang G, Chow RD, Ye L, Guzman CD, Dai X, Dong MB, et al. Mapping a functional cancer genome atlas of tumor suppressors in mouse liver using AAV-CRISPR-mediated direct in vivo screening. Sci Adv. 2018; 4: eaao5508. 
46. Pankowicz FP, Barzi M, Kim KH, Legras X, Martins CS, Wooton-Kee CR, et al. Rapid disruption of genes specifically in livers of mice using multiplex CRISPR/Cas9 editing. Gastroenterology. 2018; 155: 1967-1970.

47. Schuh RS, Poletto E, Pasqualim G, Tavares AM, Meyer FS, Gonzalez EA, et al. In vivo genome editing of mucopolysaccharidosis I mice using the CRISPR/Cas9 system. J Control Release. 2018; 288: 23-33.

48. Singh K, Evens H, Nair N, Rincon MY, Sarcar S, Samara-Kuko E, et al. Efficient in vivo liverdirected gene editing using CRISPR/Cas9. Mol Ther. 2018; 26: 1241-1254.

49. Zhang JP, Cheng XX, Zhao M, Li GH, Xu J, Zhang F, et al. Curing hemophilia A by NHEJ-mediated ectopic F8 insertion in the mouse. Genome Biol. 2019; 20: 276.

50. Chen H, Shi M, Gilam A, Zheng $Q$, Zhang $Y$, Afrikanova I, et al. Hemophilia A ameliorated in mice by CRISPR-based in vivo genome editing of human Factor VIII. Sci Rep. 2019; 9: 16838.

51. Mou H, Ozata DM, Smith JL, Sheel A, Kwan SY, Hough S, et al. CRISPR-SONIC: Targeted somatic oncogene knock-in enables rapid in vivo cancer modeling. Genome Med. 2019; 11: 21.

52. Song CQ, Jiang TJ, Richter M, Rhym LH, Koblan LW, Zafra MP, et al. Adenine base editing in an adult mouse model of tyrosinaemia. Nat Biomed Eng. 2020; 4: 125-130.

53. Villiger L, Grisch-Chan HM, Lindsay H, Ringnalda F, Pogliano CB, Allegri G, et al. Treatment of a metabolic liver disease by in vivo genome base editing in adult mice. Nat Med. 2018; 24: 1519-1525.

54. Crespo A, Peydro A, Dasi F, Benet M, Calvete JJ, Revert F, et al. Hydrodynamic liver gene transfer mechanism involves transient sinusoidal blood stasis and massive hepatocyte endocytic vesicles. Gene Ther. 2005; 12: 927-935.

55. Suda T, Gao X, Stolz DB, Liu D. Structural impact of hydrodynamic injection on mouse liver. Gene Ther. 2007; 14: 129-137.

56. Yokoo T, Kamimura K, Abe H, Kobayashi Y, Kanefuji T, Ogawa K, et al. Liver-targeted hydrodynamic gene therapy: Recent advances in the technique. World J Gastroenterol. 2016; 22: 8862-8868.

57. Ho BX, Loh JH, Chan WK, Soh BS. In vivo genome editing as a therapeutic approach. Int J Mol Sci. 2018; 19: 2721.

58. Mussolino C, Alzubi J, Pennucci V, Turchiano G, Cathomen T. Genome and epigenome editing to treat disorders of the hematopoietic system. Hum Gene Ther. 2017; 28: 1105-1115.

59. Holt N, Wang JB, Kim K, Friedman G, Wang XC, Taupin V, et al. Human hematopoietic stem/progenitor cells modified by zinc-finger nucleases targeted to CCR5 control HIV-1 in vivo. Nat Biotechnol. 2010; 28: 839-847.

60. Qasim W, Zhan H, Samarasinghe S, Adams S, Amrolia P, Stafford S, et al. Molecular remission of infant B-ALL after infusion of universal TALEN gene-edited CAR T cells. Sci Transl Med. 2017; 9: eaaj2013.

61. Chira S, Gulei D, Hajitou A, Zimta AA, Cordelier P, Berindan-Neagoe I. CRISPR/Cas9: Transcending the reality of genome editing. Mol Ther Nucleic Acids. 2017; 7: 211-222.

62. Li L, Hu S, Chen XY. Non-viral delivery systems for CRISPR/Cas9-based genome editing: Challenges and opportunities. Biomaterials. 2018; 171: 207-218.

63. Karvelis T, Gasiunas G, Siksnys V. Methods for decoding Cas9 protospacer adjacent motif (PAM) sequences: A brief overview. Methods. 2017; 121-122: 3-8. 
64. Lieber MR. NHEJ and its backup pathways in chromosomal translocations. Nat Struct Mol Biol. 2010; 17: 393-395.

65. Li X, Heyer WD. Homologous recombination in DNA repair and DNA damage tolerance. Cell Res. 2008; 18: 99-113.

66. Sonoda E, Hochegger H, Saberi A, Taniguchi Y, Takeda S. Differential usage of non-homologous end-joining and homologous recombination in double strand break repair. DNA Repair. 2006; 5: 1021-1029.

67. Hsu PD, Lander ES, Zhang F. Development and applications of CRISPR-Cas9 for genome engineering. Cell. 2014; 157: 1262-1278.

68. Wu WY, Lebbink JH, Kanaar R, Geijsen N, van der Oost J. Genome editing by natural and engineered CRISPR-associated nucleases. Nat Chem Biol. 2018; 14: 642-651.

69. Balakrishnan B, Jayandharan GR. Basic biology of adeno-associated virus (AAV) vectors used in gene therapy. Curr Gene Ther. 2014; 14: 86-100.

70. Ran FA, Cong L, Yan WX, Scott DA, Gootenberg JS, Kriz AJ, et al. In vivo genome editing using Staphylococcus aureus Cas9. Nature. 2015; 520: 186-191.

71. Peyrou M, Bourgoin L, Foti M. PTEN in non-alcoholic fatty liver disease/non-alcoholic steatohepatitis and cancer. Dig Dis. 2010; 28: 236-246.

72. Anezaki Y, Ohshima S, Ishii H, Kinoshita N, Dohmen T, Kataoka E, et al. Sex difference in the liver of hepatocyte-specific Pten-deficient mice: A model of nonalcoholic steatohepatitis. Hepatol Res. 2009; 39: 609-618.

73. Komor AC, Kim YB, Packer MS, Zuris JA, Liu DR. Programmable editing of a target base in genomic DNA without double-stranded DNA cleavage. Nature. 2016; 533: 420-424.

74. Gaudelli NM, Komor AC, Rees HA, Packer MS, Badran AH, Bryson DI, et al. Programmable base editing of $A \bullet T$ to $G \bullet C$ in genomic DNA without DNA cleavage. Nature. 2017; 551: 464-471.

75. Kim YB, Komor AC, Levy JM, Packer MS, Zhao KT, Liu DR. Increasing the genome-targeting scope and precision of base editing with engineered Cas9-cytidine deaminase fusions. Nat Biotechnol. 2017; 35: 371-376.

76 Lim CK, Gapinske M, Brooks AK, Woods WS, Powell JE, Zeballos C MA, et al. Treatment of a mouse model of ALS by in vivo base editing. Mol Ther. 2020; 28: 1177-1189.

77. Anzalone AV, Randolph PB, Davis JR, Sousa AA, Koblan LW, Levy JM, et al. Search-and-replace genome editing without double-strand breaks or donor DNA. Nature. 2019; 576: 149-157.

78. Moyo B, Bloom K, Scott T, Ely A, Arbuthnot P. Advances with using CRISPR/Cas-mediated gene editing to treat infections with hepatitis B virus and hepatitis C virus. Virus Res. 2018; 244: 311-320.

79. Niola F, Dagnaes-Hansen F, Frodin M. In vivo Editing of the adult mouse liver using CRISPR/Cas9 and hydrodynamic tail vein injection. Methods Mol Biol. 2019; 1961: 329-341.

80. Tsukamoto M, Ochiya T, Yoshida S, Sugimura T, Terada M. Gene transfer and expression in progeny after intravenous DNA injection into pregnant mice. Nat Genet. 1995; 9: 243-248.

81. Nakamura S, Watanabe S, Ando N, Ishihara M, Sato M. Transplacental gene delivery (TPGD) as a noninvasive tool for fetal gene manipulation in mice. Int J Mol Sci. 2019; 20: 5926.

82. Nakamura S, Ishihara M, Ando N, Watanabe S, Sakurai T, Sato M. Transplacental delivery of genome editing components causes mutations in embryonic cardiomyocytes of midgestational murine fetuses. IUBMB Life. 2019; 71: 835-844. 
83. Kikuchi N, Nakamura S, Ohtsuka M, Kimura M, Sato M. Possible mechanism of gene transfer into early to mid-gestational mouse fetuses by tail vein injection. Gene Ther. 2002; 9: 15291541.

84. Nakamura S, Ando N, Watanabe S, Akasaka E, Ishihara M, Sato M. Hydrodynamics-based transplacental delivery as a useful noninvasive tool for manipulating fetal genome. Cells. 2020; 9: 1744.

85. Suda T, Liu D. Hydrodynamic gene delivery: Its principles and applications. Mol Ther. 2007; 15: 2063-2069.

86. Kamimura K, Zhang G, Liu D. Image-guided, intravascular hydrodynamic gene delivery to skeletal muscle in pigs. Mol Ther. 2010; 18: 93-100.

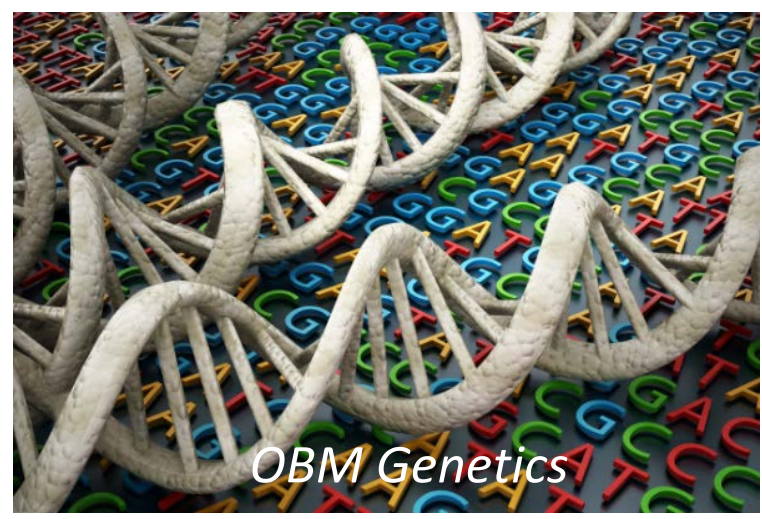

Enjoy OBM Genetics by:

1. Submitting a manuscript

2. Joining in volunteer reviewer bank

3. Joining Editorial Board

4. Guest editing a special issue

For more details, please visit:

http://www.lidsen.com/journals/genetics 